Horst, H.E. van der, Eijk, J.T.M. van, Schellevis, F.G. The effectiveness of patient education and promotion of self-care for patients with irritable bowel syndrome in primary care. Patient Education and Counseling: 1998, 34(Suppl.1) S9. Abstract.

\begin{tabular}{|l|l|}
\hline $\begin{array}{l}\text { Postprint } \\
\text { Version }\end{array}$ & 1.0 \\
\hline Journal website & http://www.pec-journal.com/article/S0738-3991\%2898\%2990012-X/abstract \\
\hline Pubmed link & $10.1016 /$ S0738-3991(98)90012-X \\
\hline DOI & \\
\hline
\end{tabular}

This is a NIVEL certified Post Print, more info at http://www.nivel.eu

\title{
The effectiveness of patient education and promotion of self-care for patients with irritable bowel syndrome in primary care
}

HORST H.E. VAN DER, EIJK JTHM VAN, SCHELLEVIS FG. Institute for Research in Extramural Medicine, van der Boechorststraat 7, 1081 BT Amsterdam.

Introduction. Patients with irritable bowel syndrome [IBS] frequently consult their general practitioner [GP] with a request for an effective therapy. However, pharmacological therapy is seldom effective and lifestyle changes and dietary measures appear to be of limited value. Various studies in recent years have explored the possibly negative influence of several factors on the course of the complaints such as persisting anxiety, avoidance behaviour and somatic attributions. In order to effectively attend to these factors, exploring, informationgiving and negotiating skills are important tools for doctors. We have developed guidelines for GPs on the management of IBS incorporating the above mentioned factors and skills and examined its effectiveness.

Methods. 29 GPs from Amsterdam, randomly allocated to either the experimental or the control group, participated in a single-blinded trial. GPs from both groups recruited patients who consulted them for non-acute abdominal complaints and who met the inclusion criteria. GPs in the experimental group received a training before they applied the guidelines. GPs in the control group administered their 'usual care'.

Results. 179 patients were included. Application of the guidelines resulted in a decrease of complaint-related anxiety and avoidance behaviour, after one and two years follow-up. Medical consumption also decreased in the experimental group. The decrease in medical consumption was most pronounced in patients with severe complaints and those showing somatic fixation according to their GP.

Conclusions. The guidelines are effective in decreasing anxiety, avoidance behaviour and medical consumption in patients with IBS in primary care. However, our intervention seems to be only partially effective as the number of self-care activities did not increase.

Adjustment of the guidelines or the training for GPs on this point should be contemplated when the implementation of our guidelines in general practice is considered. 